\title{
Embedded polar interrogatives in Turkish Sign Language
}

\author{
Emre Hakgüder (The University of Chicago) \\ hakguder@uchicago.edu
}

\begin{abstract}
Polar interrogatives in Turkish Sign Language are marked with a special head movement, HEAD FORWARD. In this study I look at the distribution of this nonmanual marker in the embedded context and show that it is likely not merely a syntactic clause-typer as previously claimed in the literature. My findings reveal that this nonmanual marker's presence and lack thereof distinguish between the semantic types question and proposition, and that it differs from its wh-counterpart, the HEAD BACKWARD, in that it is the sole syntactic clause-typer of the interrogative type, i.e. single conjunct polar, that it marks.
\end{abstract}

Keywords: interrogatives, complexity, prosody, embedded interrogatives, verb intensionality, Turkish Sign Language

\section{Introduction}

This study investigates a specific case of interaction between a nonmanual marker (henceforth NMM) and semantics in Turkish Sign Language (henceforth TİD). The NMM under the spotlight in this study is the HEAD FORWARD, a marker that has previously been associated with syntactic clause-typing of matrix polar interrogatives in TİD (Göksel and Kelepir 2013). In Hakgüder (2015), I found that TIDD morphology distinguishes wh-interrogatives that are arguments ${ }^{1}$ of intensional verbs from those of extensional verbs by the presence and absence of HEAD BACKWARD. I hypothesize that a similar pattern be observed with HEAD FORWARD in embedded polar interrogatives. The results are partially in line with embedded wh-interrogatives in that intensional predicates do in fact require the embedded polar interrogative to retain the HEAD FORWARD. Interestingly, the polar interrogative data differ in that most consultants interpreted single-conjunct polar interrogatives embedded under an extensional verb as the syntactic type declarative. This study also aims to identify the cause of that. Another aim of the study is to find the linguistic motivation behind the presence of question intonation with interrogatives embedded under intensional verbs, as embedding an interrogative clause is traditionally considered to render it non-information seeking. This study emphasizes the importance of NMMs, and therefore intonation, on the denotation of semantic items.

Section 2 presents the background on matrix polar interrogatives and embedding verb types. Section 3 lays out my methodology. Section 4 describes the TiD data and paves the way to the discussion in Section 5. Section 5 elaborates on the implications of my findings and discusses the ramifications found in the data. Section 6 concludes.

\footnotetext{
${ }^{1}$ Both Hakgüder (2015) and this paper study embedded interrogatives in both subject and object positions, the object position incidentally having more data points.
} 


\section{Background}

The first ever study to report observations on matrix polar interrogatives in TíD is Zeshan (2006). She observes widened eyes with eye gaze on the addressee and a forward head position, as well as the manual signs QUESTION.MARK ${ }^{2}$ and the PALM-UP. Göksel and Kelepir (2013) find that HEAD TILT is the morphological marker that distinguishes interrogatives from other clause types. They show that it has two morphological manifestations: (i) HEAD FORWARD marks polar interrogatives and (ii) HEAD BACKWARD marks wh-interrogatives. They conclude that these two markers syntactically distinguish interrogatives from declaratives. I follow their observations on the form of these NMMs; however, I divert from them in that I claim the function of the HEAD TILT is not to distinguish between syntactic clausetypes; but instead to mark the distinction between semantic types question ${ }^{3}$ and proposition. As for word order, polar interrogatives pattern with declaratives, i.e. the canonical SOV order. Moreover and crucially, HEAD FORWARD ${ }^{4}$ and the rarely observed QUESTION.MARK are the sole morphological indicators of a polar interrogative in TİD.

Several studies give the center stage to the semantics of interrogative embedding and the discussion revolves around the universal observation that predicates such as realize, forget, and tell differ from predicates such as ask, investigate and wonder in their semantics and possibly syntactic structure with respect to the type of the interrogative complement they take. According to Lahiri (2002), interrogative embedding predicates come in two main types, rogative and responsive. Rogative predicates such as wonder can only embed interrogatives, while responsive predicates such as know can embed both declaratives and interrogatives. Figure 1 shows the three types of embedding predicates with respect to the types of clauses they can embed.

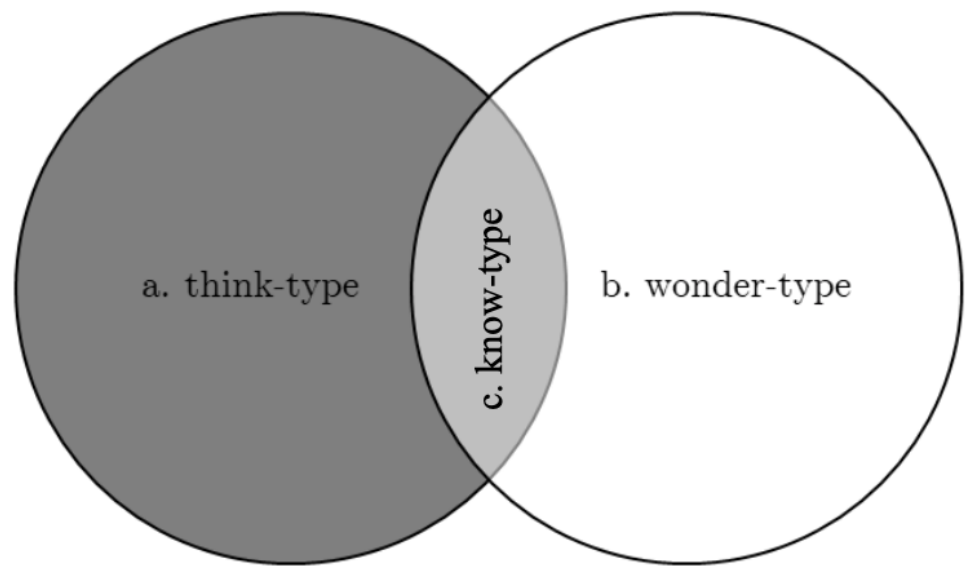

Figure 1: Embedding verbs.

Berman (1990) argues that the interrogative complements of know-type verbs differ from those of wonder-type verbs in that while the know-type interrogatives denote propositions,

\footnotetext{
${ }^{2}$ I do not report my findings on the embeddability of question mark in this paper due to space limitations.

${ }^{3}$ Throughout the paper I make the careful distinction between the terms question and interrogative, as well as proposition and declarative. Interrogative and declarative are syntactic clause types. Question and proposition are denotations.

${ }^{4}$ Göksel and Kelepir observe parasitic repetitive head nods with head forward. I will not discuss my findings on the behavior of that NMM in this paper.
} 
the wonder-type interrogatives denote questions. ${ }^{5,6}$ These verb types are sometimes called "extensional" (know-type) and "intensional" (wonder-type). In Hakgüder (2015), I show that TİD not only patterns with other languages with respect to the semantic differences between the two types, but that it also distinguishes between them in the suprasegmental tier, that is, nonmanual prosody. Crucially, I found that while intensional utterances retain the HEAD BACKWARD (abbreviated as 'hb') (1), extensionals prohibit it (2).

$\mathrm{hb}$

... WHAT THERE.IS IX-1 WONDER

'I wonder what's in (the picture).'

intensional

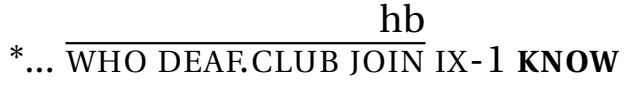

$\mathrm{hb}$

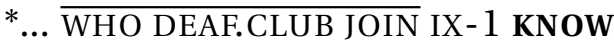

'I know who joined the deaf club.'

extensional

Examples above show the important role intonation plays in marking a semantic item's denotation, and it provides support for Berman's (1990) claim that interrogative complements of intensional predicates have a Q-morpheme. Although Berman observed that the Q-morpheme in English is phonologically null, my findings show that the Q-morpheme does not have to be null and can be found in the suprasegmental tier.

Embedded polar interrogatives in TİD do not possess a marker such as the English if or whether. The word order is also identical to that of declaratives. While semantic compatibility makes identifying the complement clauses of think- and wonder-types easy, it doesn't work with know-type verbs where the embedded clause has no segmental or suprasegmental indication whether it is a declarative or a polar interrogative (3).

\section{IX-2 [MELTEM ENGLAND MOVE] KNOW}

One could expect, depending on previous observations on embedded wh-interrogatives and assuming the matrix clause is a declarative, that the string of signs above can have the following two interpretations if NMMs are not taken into account:

a. You know that Meltem moved to England.

b. You know whether Meltem moved to England.

To account for the discrepancy in (3), we could try to look at NMMs. However, making an analogy from my previous observation on HEAD BACKWARD (examples 1 and 2), one could expect that HEAD FORWARD found in information-seeking matrix polar questions is likely to mark polar interrogative complements of intensional verbs, but not those of extensionals, which the verb KNOW is one. It is the absence of HEAD FORWARD, the only morphological indicator of the polar interrogative, with the complement of KNOW in (3) that causes the two-way ambiguity in (a) and (b). However, further into the paper, we will see that the single conjunct polar interrogative interpretation in (b) is not possible altogether.

English (Eckardt 2001) and ASL (Davidson and Caponigro 2016) are two other languages where extensional and intensional embedders act differently. Intensional verbs in English can embed both if and whether polar interrogatives, while extensional verbs can only embed

\footnotetext{
${ }^{5}$ For evidence and a discussion on how the two types differ see Quantificational Variability Effect (Hintikka 1976; Berman 1990).

${ }^{6}$ See also Groenendijk and Stokhof $(1982,1984)$ and Spector and Egré (2015).
} 
whether polar interrogatives. ${ }^{7}$ As for ASL, signers can interpret the complement clause in 4 only as a declarative.

(4) MOM KNOW [BROTHER LIKE THAT SALAD]

(a) 'Mom knows that my brother likes that salad.'

(b) \#'Mom knows whether my brother likes that salad.'

Building on those observations, I raise the questions whether TİD embedded polar interrogatives behave similarly, and if so what causes the discrepancy.

\section{Methodology}

I use two elicited datasets collected in Spring 2016 and Summer 2017 at the Boğaziçi University Sign Language Lab. There are a total of 101 data points consisting of matrix polar, embedded polar, embedded alternative interrogatives, and embedded declaratives. The data were collected from one female native deaf signer in her late thirties. She was given 25 scenarios consisting of real and hypothetical events featuring her family members and friends. I signed each scenario to her and expected her to produce an embedded polar interrogative as an answer:

\section{(5) a. Researcher:}

There was a car accident. Your car is badly damaged. But the car insurance you got was cheap, and you don't know what will happen. You're telling your friends about the accident and you're worried. What would you say to your friends?

b. Consultant:

ACCIDENT HAPPEN. CAR DAMAGED BAD. INSURANCE ACCIDENT^FOR PAY CLEAR^NOT. 'I was in an accident. (My) car is damaged badly. Whether the insurance will pay for the accident is not clear.'

After collecting pilot data, I prompted her to modify the sentences minimally along the lines of my research questions until I had sets of the following data types from the most common verbs WONDER, KNOW and KNOW`NOT (Table 1).

\begin{tabular}{|l|l|c|c|}
\hline \multirow{2}{*}{$\begin{array}{l}\text { (i) Embedded polar } \\
\text { interrogative }\end{array}$} & \multicolumn{2}{c|}{$\begin{array}{c}\text { Matrix } \\
\text { word order }\end{array}$} \\
\cline { 3 - 4 } & & VO & OV \\
\hline \multirow{2}{*}{ QUESTION.MARK } & yes & $\mathrm{x}$ & $\mathrm{x}$ \\
\cline { 2 - 4 } & no & $\mathrm{x}$ & $\mathrm{x}$ \\
\hline
\end{tabular}

\begin{tabular}{|l|l|c|c|}
\hline \multirow{2}{*}{$\begin{array}{l}\text { (ii) Embedded alternative } \\
\text { interrogative }\end{array}$} & \multicolumn{2}{|c|}{$\begin{array}{c}\text { Matrix } \\
\text { word order }\end{array}$} \\
\cline { 3 - 4 } & VO & OV \\
\hline \multirow{2}{*}{ QUESTION.MARK } & yes & $\mathrm{x}$ & $\mathrm{x}$ \\
\cline { 2 - 4 } & no & $\mathrm{x}$ & $\mathrm{x}$ \\
\hline
\end{tabular}

Table 1: Data types.

Table 2 breaks the verbs I used into two groups and gives the number of data points I have with each verb.

Note that adding matrix negation to an extensional verb can make it intensional. We see this with KNOW and REMEMBER. Another way extensionals can be made intensional is by turning the root clause into a polar question. This is indicated with a question mark next to

\footnotetext{
${ }^{7}$ Speaker judgments differ, however, for a syntactic account see Adger and Quer (2001). Eckardt (2001) gives a pragmatic account.
} 


\begin{tabular}{|l|l|}
\hline Intensional \\
\hline WONDER & 21 \\
\hline ASK & 5 \\
\hline WONDER^NOT & 2 \\
\hline FIND.OUT WANT & 5 \\
\hline KNOW^NOT & 19 \\
\hline REMEMBER^NOT $^{\wedge}$ & 11 \\
\hline DEFINITE^NOT & 1 \\
\hline CLEAR^NOT & 3 \\
\hline GUESS? & 1 \\
\hline NEWS THERE.IS? & 3 \\
\hline FORGOT & 4 \\
\hline SAY? & 3 \\
\hline $\begin{array}{l}\text { THINK (DO SOUL } \\
\text { SEARCHING) }\end{array}$ & 3 \\
\hline
\end{tabular}

\begin{tabular}{|l|l|}
\hline \multicolumn{2}{|l|}{ Extensional } \\
\hline KNOW & 8 \\
\hline FIND.OUT & 7 \\
\hline GUESS & 1 \\
\hline
\end{tabular}

Table 2: Matrix verbs.

such verbs. The data were clipped and annotated in ELAN for data type, word order and the spreading of NMMs. Due to space limitations, I do not share the coding scheme here.

In addition, I devised two judgment tests where 7 native TİD signers participated. The first one is an acceptability judgment test that uses a 7-point Likert scale. The second is a preference test. The acceptability judgment test shows items one video at a time and asks three questions:

i. How many sentences do you see in the video? (they are asked to select 1 or 2)

ii. Give your judgment on this video on a scale from 1 to 7 .

The question in (i) aims to tell whether the signers perceive the embedded clause as a separate sentence or as an internal part of the root clause. While this paper is not concerned with providing evidence in favor of TİD's capability to embed clauses, question (i) is important in interpreting each score participants have given to each sentence in question (ii), especially the unexpected ones. The question in (ii) aims to test whether there are any word order asymmetries with respect to verb intensionality. I use the arithmetic mean of the participants' answers for each data point as a standing point due to the small scale of the project. The mean is given below each example. The third question is tailor-made for each video and aims to test whether the answer to the embedded interrogative is presupposed by the matrix verb. In one such section, signers first watch a stimulus video (6).

(6) SUMRU LOTTERY WIN IX-1 WONDER

'I wonder whether Sumru won the lottery.'

The signers are then asked the following question and given three answers to choose from: 
iii. Did Sumru win the lottery?

a. Yes.

b. No.

c. Uncertain.

These questions are designed to tell whether interrogatives embedded under extensional verbs are interpreted as a semantic question or a proposition. If signers chose "uncertain" it indicates that the embedded clause is a question, if they chose "yes" or "no", then the embedded clause is a semantic proposition.

The second is a forced choice task between two videos. This test presents utterances to the signer ranging from pairs that have a near-identical grammaticality judgment score obtained from the previous 7 -scale range to pairs whose scores are greatly different. The aim of this test is to tell which utterances are more preferable over the others. For instance, if VO and OV orders with an intensional verb scored 6.9 and 6.7 respectively, this test is used to determine which one is preferred when the test subject is asked to choose between the two.

\section{Embedded polar questions in TíD}

This section describes the data in the light of the two judgment tests. The aim of this section is to lay out the linguistic observations I made around the structure and to pave the way to Section 5 where I discuss the linguistic implications of my observations. The first subsection (Section 4.1) presents data with respect to different verb categorizations. Section 4.2 reports my findings on matrix and embedded word orders, Section 4.3 presents my findings on the HEAD FORWARD.

\subsection{Verb types}

Embedding verbs can be classified with respect to different criteria. The two criteria that are crucial to my discussion here are (i) whether they embed interrogative clauses or declarative clauses, or both, and (ii) whether the embedding verb is intensional or extensional.

Coordination is a test that has been used to determine which verbs fall in which embedding category with respect to the types of complements they can embed (Lahiri 1991; Elliott et al. 2017). Coordinating a declarative ${ }^{8}$ and an interrogative yields different results with different embedding verbs in the root clause:

*IX-1 CLAim [[ALI.BULUT HOME] [KUNTAY WHERE GO]]

'I claim that Ali Bulut is at home and where Kuntay went.'

(8) *IX-1 [[ALI.BULUT HOME] [KUNTAY WHERE GO]] WONDER

'I wonder that Ali Bulut is at home and where Kuntay went.'

(9) IX-1 KNOW [[ALI.BULUT HOME] [KUNTAY WHERE GO]]

'I know that Ali Bulut is at home and where Kuntay went.'

\footnotetext{
${ }^{8}$ Note that the declarative complement [ALI.BULUT HOME] in each example has REPETITIVE HEAD NODS spreading over the entire predicate, i.e. HOME, lacks brow movements, the eyes are neutral, and HEAD FORWARD is not present. These prosodic cues signal that the embedded clause can only be interpreted as a declarative (i.e. "Ali Bulut is at home.") as opposed to a polar interrogative (i.e. “Is Ali Bulut at home?").
} 
The examples in (7-9) show that while a verb like KNOW (9) is compatible with both an interrogative complement and a declarative complement, WONDER (8) and CLAIM (7) cannot embed two coordinated complements that are of different clause types. WONDER is compatible only with an interrogative complement and CLAIM only with a declarative complement. The examples above confirm the existence of the three verb types in TID. In the following subsection, I report my findings on verb intensionality and its interaction with word order.

\subsection{Word order}

The canonical word order of TİD is SOV (Açan 2001; Sevinç 2006; Kubuş 2008; Gökgöz 2009). Göksel and Kelepir (2016) found that, despite the canonical word order, signers prefer matrix SVO order when embedding a declarative under a know-type verb. In Hakgüder (2015), I found that signers prefer utterances with a wh-complement and an extensional verb in VO order and those with an intensional verb in OV order. ${ }^{9}$ The following examples present my findings on the position of the verb in relation to its complement ${ }^{10}$ in embedded polar interrogatives.

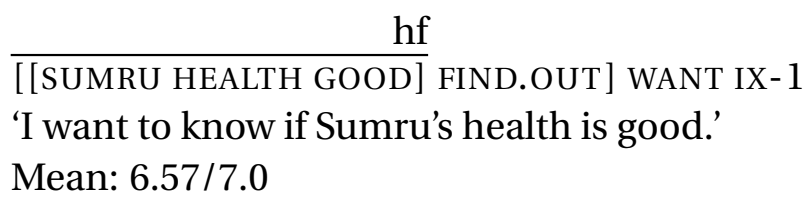

hf

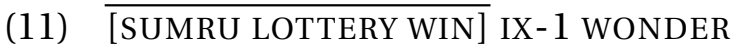
OSV $^{11}$

'I wonder whether Sumru won the lottery.'

Mean: $6.71 / 7.0$

(12) ?IX-1 WONDER $\frac{\text { hf }}{\text { [MELTEM ENGLAND MOVE] }}$ $\mathrm{S}[\mathrm{VO}]$ Int.: 'I wonder whether Meltem moved to England.'

Mean: $4.57 / 7.0$

The sentences above show that embedded polar interrogatives in TİD pattern with embedded wh-interrogatives and prefer a matrix OV order if the verb is intensional. Note that I do not claim that the VO order in the examples above are ungrammatical, but OV order scores are higher with intensional verbs than the VO order. The following are examples with extensional verbs. Note that for each example there is a version with HEAD FORWARD and one without.

(13) IX-1 KNOW [MELTEM ENGLAND MOVE] $\mathrm{S}[\mathrm{VO}]$

Int.: 'I know whether Meltem moved to England.' Interpreted as: 'I know that Meltem moved to England..' Mean: 6.85/7.0

(14) ?IX-1 KNOW [MELTEM ENGLAND MOVE] $\mathrm{S}[\mathrm{VO}]$

Int.: 'I know whether Meltem moved to England..' Mean: 3.83/7.0

\footnotetext{
${ }^{9}$ A similar word order asymmetry with respect to verb intensionality was observed in Brazilian Sign Language in Napoli, Spence, and Quadros (2017).

${ }^{10}$ In this study I do not look at the position of the subject pronoun.

${ }^{11}$ This order is probably the result of object topicalization from an underlying SOV order. However, I do not have a definitive answer to whether topicalization has actually taken place.
} 
(15) ?IX-1 [MELTEM ENGLAND MOVE] KNOW

$\mathrm{S}[\mathrm{OV}]$

Int.: 'I know whether Meltem moved to England..'

Mean: 5.28/7.0

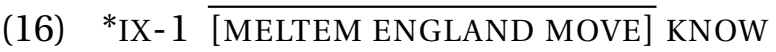

$\mathrm{S}[\mathrm{OV}]$

Int.: 'I know whether Meltem moved to England..'

Mean: 1.85/7.0

We see a stronger effect of word order on grammaticality in extensional verbs than in intensional verbs. The HEAD FORWARD renders extensional constructions uncceptable, which is predicted by my past observation on embedded wh-interrogatives. Interestingly though, the lack of polar question intonation (i.e. HEAD FORWARD) makes these complements identical in form to embedded declaratives, therefore there is a strong possibility that the signers interpreted these as embedded declaratives (13) and scored them high, to my surprise. I discuss this issue further in Section 5 in the light of the answers participants gave to the third question of the grammaticality judgment task.

I will not discuss my findings on embedded word order due to space limitations; however, suffice it to say that TİD can embed both double conjunct polar interrogatives (i.e. "A or notA") and alternative interrogatives (i.e. "A or B"), and that using either strategy allows for an interrogative interpretation when the matrix verb is extensional, unlike a single conjunct interrogative (13), which does not allow the same interpretation.

\subsection{The HEAD FORWARD}

The HEAD FORWARD has an important status in this study. ${ }^{12}$ It is an obligatory marker of matrix polar interrogatives and of those embedded under intensional verbs:

(17) [SUMRU LOTTERY WIN] IX-1 WONDER

'I wonder whether Sumru won the lottery.'

Mean: $6.71 / 7.0$

(18) *[SUMRU LOTTERY WIN] IX-1 WONDER

Int.: 'I wonder whether Sumru won the lottery.'

Mean: 1.85/7.0

6 out of 7 signers said example (18) has two sentences, whereas only 1 signer thinks the example in (17) has two separate sentences. This shows that HEAD FORWARD is obligatory with an interrogative embedded under an intensional verb, and if it is missing, the signers interpret the utterance as having two separate sentences. The mean of participant scores to the example in (18) shows that the interpretation of a proposition followed by "I wonder" yields a nonsense reading, such as "Sumru won the lottery. I wonder."

This is further supported by the final question I asked to signers in the grammaticality judgment task. 6 out of signers answered "Yes" to the question "Did Sumru win the lottery?". This means that those 6 signers interpreted [SUMRU LOTTERY WIN], which is without HEAD FORWARD, as a declarative.

\footnotetext{
${ }^{12}$ In this paper, I do not report my findings on other nonmanual markers such as HEAD SHAKE, BROW RAISE and the mouthing of QUESTION.MARK due to space limitations.
} 


\section{The function of HEAD FORWARD and the know-type puzzle}

In Hakgüder (2015) I've shown that the HEAD BACKWARD cannot be generalized as the syntactic marker of wh-interrogatives, as it is only observed in wh-interrogatives embedded under intensional verbs besides matrix information seeking wh-interrogatives. This was an interesting finding in that it showed an overt morphological asymmetry between two embedding verb types that have been reported in the literature to behave differently in the semantics component, and that it also showed that even though the syntactic clause type is an interrogative, it does not always need to be marked with HEAD BACKWARD, contrary to what Göksel and Kelepir's findings would predict. Therefore, I claimed that the HEAD BACKWARD is a marker of a nature other than a syntactic one, and that it possibly distinguishes the semantic type question from the semantic type proposition. While the lack of HEAD BACKWARD did not pose a problem to my analysis then, the lack of HEAD FORWARD with extensional verbs does. Its absence when embedded under extensional verbs basically deletes the only salient marker of the single conjunct polar interrogative in TID, and the signers interpret those cases as embedded declaratives, which could be interpreted as evidence that the HEAD FORWARD is indeed a syntactic marker. However, I will refrain from choosing between syntactic clause-typer and semantic type marker as the probable function of the HEAD FORWARD, as the question becomes philoshophical.

The lack of HEAD FORWARD or HEAD BACKWARD with extensional verbs can easily be accounted for by the well-known semantic extensional-intensional difference. On the flip, the presence of question intonation with intensional verbs is surprising too, since embedded interrogatives are not necessarily posing a direct question. One could argue that the function that these two NMMs mark is eliciting an answer. While at first this seems to contradict the intuition that embedded interrogatives are not direct questions, they could very well be received as questions faced by an interlocutor (see Dekker, Aloni, and Butler 2007). Consider the TİD conversations in (19-20). A is a speaker; R1, R2 and R3 are alternative responses of their interlocutor to A.

(19) A: [WHO TID TEACH NEXT^^YEAR] WONDER IX-1

intensional

'I wonder who will teach TİD next year.'

R1: NEXT^ ${ }^{\wedge}$ YEAR ELVAN TID TEACH

'Elvan will teach TİD next year.'

R2: \#WHO TID TEACH NEXT^ ${ }^{\wedge}$ YEAR IX-2 KNOW

'Do you know who will teach TíD next year?'

(20) A: IX-1 KNOW [WHO TID TEACH NEXT^YYEAR]

extensional

'I know who will teach TİD next year.'

R1: IX-1 SAME. IX-1.

'Me too. I will.'

R2: 1-SAY-2. IX-1 QUESTION.MARKER?

'Tell me! Is it me?'

Responding to an interrogative embedded under an intensional verb with a question is odd (19-R2), while responding to an extensional with a question is perfectly acceptable (20-R2). In the first conversation (19), the speaker (A) is asserting their lack of knowledge about the identity of the person who will teach TİD and also their state of mind regarding the issue, i.e. wonder. In the second conversation (20), the speaker indicates that they know the identity of the TİD teacher, but instead of sharing that piece of information with the interlocutor, they 
stop at expressing that they have the knowledge and do not reveal the future teacher's identity. Therefore, the interlocutor (20-R2) is able to seek to elicit the answer from the speaker with a direct question.

While the test above could be used as indirect evidence to show that the HEAD BACKWARD marks the semantic type question in embedded wh-interrogatives, the same test cannot be used for HEAD FORWARD, because in its absence in the extensional environment signers interpret the embedded string of words as a declarative, not as a polar interrogative:

\section{(21) IX-1 KNOW [MELTEM ENGLAND MOVE] \\ 'I know that Meltem moved to England.' \\ Mean: 6.85}

While my initial intention in eliciting this piece of data and putting it out there for grammaticality judgment was to study whether or not embedding polar interrogatives under extensional verbs in TIDD pattern with embedded wh-interrogatives in the dropping of the question intonation, what I ended up finding has been that TİD signers do not interpret those as embedded polar interrogatives at all. Instead, they interpret them as embedded declaratives that denote a proposition. This is clear from the results of the grammaticality judgment test. They scored such data points high (6.85/7 in the case of (19)) and interpreted them as composed of a single sentence (6 out of 7 signers), both of which contradicted my expectation that they would find them semantically odd, interpret them as two separate sentences such as "I know. Did Meltem move?", and therefore score them low. Moreover, when they were asked whether Meltem moved to England, again 6 out of 7 signers responded "Yes", while only 1 responded "Uncertain", which supports my claim that they interpret it as an embedded declarative. The uninterpretability of the interrogative (i.e. "set of alternatives") reading seems to stem from the lack of a morphological marker to distinguish an embedded polar interrogative from an embedded declarative. ${ }^{13}$

\section{Conclusion}

In this study I tackled issues relating to the semantics, word order and intonation in embedded polar interrogatives in TID. I've claimed that TID uses HEAD FORWARD to distinguish extensional and intensional constructions, and that this marker may not be not a syntactic clause-typer but instead an intonational cue, or possibly a morpheme that distinguishes between the semantic types question and proposition. I've made this claim based on my observations on the asymmetric behavior of the HEAD FORWARD between extensional predicates and intensionals with respect to what it means to assert a semantic question even in the embedded context. I've also found that single conjunct polar interrogatives embedded under extensional verbs cannot be interpreted as an interrogative, a condition also observed in other languages. They denote semantic propositions and the lack of HEAD FORWARD results in a syntactic declarative interpretation.

\footnotetext{
${ }^{13}$ Note that TỉD signers may use a double conjunct polar interrogative which resembles "whether or not" in English. The presence of other means to express this meaning shows that TiD does not have a semantic or pragmatic restriction against embedding polar interrogatives under extensionals. I will leave it at that due to space restrictions.
} 


\section{References}

Açan, Zeynep. 2001. "A study on sign languages and Turkish Sign Language”. MA thesis, Ankara University.

Adger, David, and Josep Quer. 2001. "The Syntax and semantics of unselected embedded questions". Language 77 (1): 107-133.

Berman, Steve. 1990. "Towards a semantics of open sentences: wh-phrases and indefinites". In Proceedings of the Seventh Amsterdam Colloquium, ed. by Martin Stokhof and Leen Torenvliet, 53-77. Amsterdam: ILLC.

Davidson, Kathryn, and Ivano Caponigro. 2016. "Embedding polar interrogative clauses in American Sign Language”. In A matter of complexity: Subordination in sign languages, ed. by Roland Pfau, Markus Steinbach, and Annika Herrmann, 151-181. Berlin: De Gruyter Mouton.

Dekker, Paul, Maria Aloni, and Alastair Butler. 2007. "The semantics and pragmatics of questions”. In Questions in Dynamic Semantics, ed. by Maria Aloni, Alastair Butler, and Paul Dekker, 1-40. Leiden: Brill Publishing.

Eckardt, Regine. 2001. “The syntax and pragmatics of embedded yes/no questions”. In On information structure, meaning, and form, ed. by Kerstin Schwabe and Susanne Winkler, 447-466. Amsterdam: John Benjamins.

Elliott, Patrick D., Nathan Klinedinst, Yasutada Sudo, and Wataru Uegaki. 2017. "Predicates of relevance and rheories of question embedding”. Journal of Semantics. doi:10 . 1093/ jos/ffx008.

Gökgöz, Kadir. 2009. “Topics in Turkish Sign Language syntax: Verb movement, negation and clausal architecture”. MA thesis, Boğaziçi University.

Göksel, Asl1, and Meltem Kelepir. 2013. "The phonological and semantic bifurcation of the functions of an articulator: HEAD in questions in Turkish Sign Language”. Sign Language \& Linguistics 16 (1): 1-30. doi:10.1075/sll.16.1.01gok.

— .2016. "Observations on clausal complementation in Turkish Sign Language". In A matter of complexity: Subordination in sign languages, ed. by Roland Pfau, Markus Steinbach, and Annika Herrmann, 65-94. Berlin: De Gruyter Mouton.

Groenendijk, Jeroen, and Martin Stokhof. 1982. "Semantic analysis of "wh"-complements". Linguistics and Philosophy 5 (2): 175-233.

— . 1984. "Problems and prospects in the theory of questions". In Studies on the semantics of questions and the pragmatics of answers, ed. by Jeroen Groenendijk and Martin Stokhof. Amsterdam: Juriaans.

Hakgüder, Emre. 2015. "Complex clauses with embedded constituent interrogatives in Turkish Sign Language (TID).” MA thesis, Boğaziçi University.

Hintikka, Jaakko. 1976. "The semantics of questions and the questions of semantics". Acta Philosophica Fennica 28:369-416.

Kubuş, Okan. 2008. “An analysis of Turkish Sign Language phonology and morphology”. Diploma thesis, Middle East Technical University.

Lahiri, Utpal. 1991. “Embedded interrogatives and predicates that embed them”. Doctoral dissertation, MIT. 
— . 2002. Questions and answers in embedded contexts. New York: Oxford University Press.

Napoli, Donna Jo, Rachel Sutton Spence, and Ronice Müller de Quadros. 2017. "Influence of predicate sense on word order in sign languages: Intensional and extensional verbs". Language 93 (3): 641-670. doi:10.1353/lan.2017. 0039.

Sevinç, Ayça. 2006. “Grammatical relations and word order in Turkish Sign Language”. MA thesis, Middle East Technical University.

Spector, Benjamin, and Paul Egré. 2015. "A uniform semantics for embedded interrogatives: an answer, not necessarily the answer”. Synthese 192, no. 6 (): 1729-1784. doi:10.1007/ s11229-015-0722-4.

Zeshan, Ulrike. 2006. "Negative and interrogative structures in Turkish Sign Language". In Interrogative and negative constructions in sign languages, ed. by Ulrike Zeshan, 128-164. Nijmegen: Ishara Press. 